ДЕЛЕНЬЯН Б.А.

РЕГИОНАЛЬНАЯ ИНФРАСТРУКТУРА КАК ОСНОВА СИСТЕМНОГО РАЗВИТИЯ ЭКОНОМИКИ СОВРЕМЕННОГО РЕГИОНА: ПОСТАНОВКА ПРОБЛЕМЫ И ОРГАНИЗАЦИОННО-ЭКОНОМИЧЕСКОЕ ОБЕСПЕЧЕНИЕ

\title{
РЕГИОНАЛЬНАЯ ИНФРАСТРУКТУРА КАК ОСНОВА СИСТЕМНОГО РАЗВИТИЯ ЭКОНОМИКИ СОВРЕМЕННОГО РЕГИОНА: ПОСТАНОВКА ПРОБАЕМЫ И ОРГАНИЗАЦИОННО-ЭКОНОМИЧЕСКОЕ ОБЕСПЕЧЕНИЕ
}

Аннотация. Цель работы - развитие действующей методологии регионального инфра стоуктурного обеспечения транспортных процессов на основании авторского подхода к рассмотрению транспортной инфраструктуры как базиса системного регионального экономического развития. Методология работы: авторский научный поиск в части усовершенствования организащионно-экономического обеспечения прочессов формирования, функционирования и развития региональной транспортной инфраструктуры, полевое исследование состояния и перспектив функционирования и развития региональной инфраструктуры морского транспорта РФр, представленной в Краснодарском крае в контексте усиления его стратегического значения в составе транспортного комплекса Южного федерального округа. Результаты работы: развитие инфраструктурной теории региональной экономики в части усовершенствования организационно-экономического обеспечения процессов создания, эксплуатачии и модернизащии объектов региональной транспортной инфраструктуры, ориентированных на реализацию ее системного потенциала в качестве фундаментального фактора стратегического развития региональных экономических систем. Область применения результатов: государственная и корпоративные стратегии развития региональной транспортной инфраструктуры на среднесрочную и долгосрочную перспективу, отраслевые челевые комплексные программы, программы комплексного освоения территорий. Выводы: обоснованы роль и значение региональной транспортной инфраструктуры Южного федерального округа как фундаментального системного преимущества регионального транспортного комплекса и экономики территории в целом, обладающего как общеорганизационным, так и собственным экономическим значением и резервами роста конкурентоспособности и экономической эффективности. Авторский подход учитывает необходимость выработки и реализащии долгосрочной инфраструктурной стратегии функционирования и развития, сочетающей направление роста операџионной эффективности инфраструктурного обслуживания транспортных процессов с инновационным направлением прорывного роста инфраструктурных функииональных возможностей регионального и межрегионального масштабов.

Кмючевые слова: региональная транспортная инфраструктура, пространственная организация экономики, региональная экономическая система.

DELENYAN BORIS ALEXANDROVICH

candidate of the Department of applied Economics and Economics security of the Federal state educational INSTITUTION "NRU Belgu",

e-mail:Delenjan@mail.ru

\section{REGIONAL INFRASTRUCTURE AS THE BASIS FOR THE SYSTEM DEVELOPMENT OF THE ECONOMY OF A MODERN REGION: PROBLEM STATEMENT AND ORGANIZATIONAL AND ECONOMIC SUPPORT}

Abstract. The purpose of this work is to develoo the current methodology of regional infrastructure support for transport processes based on the author's approach to the consideration of transport infrastructure as the basis of systemic regional economic development. Research methodology: author's research in terms of improving the organizational and economic support of the processes of formation, operation and development of regional transport infrastructure, field re- 
search of the state and prospects for the functioning and development of regional Maritime transport infrastructure of the Russian Federation, presented in the Krasnodar territory in the context of strengthening its strategic importance as part of the transport complex of the southern Federal district. Results: development of the infrastructure theory of the regional economy in terms of improving the organizational and economic support for the creation, operation and modernization of regional transport infrastructure facilities, aimed at realizing its systemic potential as a fundamental factor in the strategic development of regional economic systems. Scope of the results: state and corporate strategies for the development of regional transport infrastructure in the medium and long term, industry-specific integrated programs, programs for integrated development of territories. Conclusions: the role and importance of regional transport infrastructure in southern Federal district as a fundamental system the benefits of regional transport complex and economy of the territory as a whole, possessing both enterprise and private economic value and reserves of competitiveness and economic efficiency. The author's approach takes into account the need to develop and implement a long-term infrastructure strategy for functioning and development, which combines the direction of increasing the operational efficiency of infrastructure services for transport processes with an innovative direction of breakthrough growth of infrastructure functionality of regional and interregional scales.

Keywords: regional transport infrastructure, spatial organization of the economy, regional economic system.

Введение. В настоящее время перед Российской Федерацией поставлены по-настоящему масштабные цели и задачи инфраструктурной модернизации, от прикладной реализации которых будет зависть реализация эффективности достижения стратегических приоритетов каждого из регионов нашей страны в XXI веке. Необходимо подчеркнуть, что развитие экономики регионов наибольшей по площади страны мира, включающей в себя ряд локальных систем со значимыми пространственными границами - барьерами -невозможно без эффективного транспортного сообщения, обладающего системной экономической значимостью и вносящего фундаментальный вклад в конкурентоспособность и эффективность национальной экономической модели, особенно с учетом территориальных ресурсов Российской Федерации.

Основные компоненты региональной транспортной инфраструктуры в Российской Федерации и ее федеральных округах, в частности ЮФО, обладают собственным уникальным набором конкурентных преимуществ и слабых мест, который должен учитываться в составе перспективной Транспортной стратегии развития Российской Федерации и увязанных с ней региональных инфраструктурных стратегий. Отдельной народнохозяйственной задачей регионального развития в современных условиях становится планирование и реализация межотраслевого транспортного взаимодействия в формате мультимодальных перевозок в пределах национальных и международных грузопотоков.

Следует подчеркнуть, что морской транспорт Российской Федерации является стратегическим компонентом национальной транспортной системы и обладает в настоящее время значимыми резервами роста народнохозяйственной эффективности, которые могут и должны быть реализованы в отношении его позитивного влияния в качестве фундаментального фактора, способного в значительной мере повысить устойчивость и поступательность функционирования и развития экономики Российской Федерации. Указанная реализация возможна только с учетом особенностей и перспектив модернизации региональной портовой транспортной инфраструктуры, являющейся сегодня достаточно «узким местом» в части обслуживания региональных, национальных и международных транспортных потоков.

Авторский подход к пониманию и исследованию проблем создания, эксплуатации и модернизации объектов региональной, в том числе транспортной, инфраструктуры ориентирован на ее характеристику в качестве объективной основы и фундаментального фактора развития региональных экономических систем и включает в себя следующие ключевые аспекты:

1. Инфраструктура как опорный каркас региональной экономической системы: стратегическая и операционные функции.

2. Региональная инфраструктура как связующий механизм, обеспечивающий возможность использования ресурсов экономического пространства в экономической системе территории 
РЕГИОНАЛЬНАЯ ИНФРАСТРУКТУРА КАК ОСНОВА СИСТЕМНОГО РАЗВИТИЯ ЭКОНОМИКИ СОВРЕМЕННОГО РЕГИОНА: ПОСТАНОВКА ПРОБЛЕМЫ И ОРГАНИЗАЦИОННО-ЭКОНОМИЧЕСКОЕ ОБЕСПЕЧЕНИЕ

на основе формирования региональной экономической среды.

3. Инфраструктурный и бесструктурный сценарии организации региональных экономических процессов.

4. Субъекты, процессы и результаты использования инфраструктурных возможностей и потенциала в региональных экономических процессах.

5. Региональная транспортная инфраструктура в составе инфраструктуры экономики региона: определение, функции, цели, задачи, субъекты, процессы, особенности формирования, операционные и народнохозяйственные результаты.

Авторская позиция в части обоснования народнохозяйственной роли, стратегической и операционных функций региональной инфраструктуры как опорного каркаса региональной экономической системы представлена на рис. 1.

В нашем представлении инфраструктура является звеном, обеспечивающим связь и возможность использования наличных ресурсов территории в деятельности региональной экономической системы как совокупности производительных, социальных и воспроизводственных субъектов и институтов.

Региональное экономическое пространство (экономический потенциал территории) - совокупность представленных в пределах конкретной территории ресурсов всех видов, доступных к мобилизации и использованию субъектами региональной экономики

Региональная инфраструктура - совокупность систем, субъектов и элементов, обеспечивающих возможности использования наличных (из регионального экономического пространства) и дефицитных (путем использования межрегиональных экономических связей) ресурсов в деятельности субъектов и институтов экономики региона

Стратегическая функция региональной инфраструктуры - формирование региональной экономической среды как совокупности систематизированных, оцененных, мобилизованных и готовых к использованию ресурсов, необходимых для инициации экономических процессов субъектами, представленными в экономике региона

Подфункции региональной инфраструктуры:

1. Возможность инициации и безопасного ведения легальной экономической деятельности различными субъектами и институтами, локализованными в пределах региональной экономической системы.

2. Возможность получения положительного операционного результата экономической активности за счет использования абсолютных и относительных преимуществ территории региона.

3. Равный и справедливый доступ к инфраструктурным ресурсам (факторам производства, товарам, услугам, информации), необходимым для инициации экономической деятельности (систематизация наличия и оценки экономической эффективности использования представленных в пределах территории ресурсов, региональный и межрегиональный маневр).

4. Демпфирование колебаний ценовой и неценовой региональной экономической конъюнктуры за счет внутренних запасов и резервов, а также регулирующих управленческих воздействий.

5. Региональная инфраструктура как совокупность специфических видов деятельности, на основе которых возможны появление, развитие, функционирование коммерческих и некоммерческих структур - субъектов и институтов региональной экономики.

6. Вклад в формирование основных (ВРП, инфраструктуроемкость ВРП) и конечных (доходы населения работников и собственников) результатов функционирования региональной экономической системы.

Pис. 1. Инфраструктура как опорный каркас региональной экономической системы (авторская разработка).

Ключевыми признаками авторского определения региональной инфраструктуры являются:

- рассмотрение ее субъектов с точки зрения их возможности обеспечения доступа пользователей к наличным (имеющимся в региональном экономическом пространстве) и дефицитным (доступным к импорту) ресурсам, необходимым для функционирования цепочек создания ценности региональных экономических структур и субъектов;

- распределение инфраструктурных запросов пользователей в региональной инфраструктурной сети как совокупности поставщиков, дифференцированных по типу инфраструктурных товаров и услуг, но объединенных общностью их использования;

- выполнение запросов и удовлетворение потребностей в инфраструктурных благах поставщик осуществляет в отношении множества потребителей, в числе которых могут быть инфра- 
структурные узлы низшего уровня (межрегиональные - региональные - локальные инфраструктурные узлы), корпоративные потребители и домохозяйства;

- необходимость и целесообразность организации инфраструктурного типа ресурсного обеспечения региональной экономической системы обоснована возможностью реализации принципов специализации и кооперации, обеспечивающих кратный рост производительности в сравнении с самостоятельным обеспечением каждого потребителя всем спектром инфраструктурных благ;

- снижение стоимости доступа пользователей к инфраструктурным благам, обоснованное эффектом масштаба их производства.

Особенности инфраструктуры как структурообразующего компонента региональной экономической среды и системы отражены на рис. 2. В авторском понимании региональная инфраструктура в целом характеризуется дуалистической ролью, реализуемой в ходе организации регионального экономического процесса:

- она обеспечивает возможность трансформации имеющихся в пределах конкретной территории разрозненных ресурсов в единую региональную экономическую среду, предоставляющую субъектам экономики региона возможности доступа к совокупности систематизированных и готовых к использованию в экономической деятельности факторов производства;

- она является разновидностью пространственно-локализованной сетевой экономической системы, позволяющей организовать последовательный процесс запросов на удовлетворение инфраструктурных потребностей и его исполнение со стороны специализированных поставщиков, по сути выступая экономическим «фундаментом» региональных экономических процессов всех видов и выполняя опорную, демпфирующую функции, функцию экономии производительных ресурсов и безопасного и надежного доступа к инфраструктурным экономическим возможностям.

Необходимо подчеркнуть, что инфраструктурный тип развития экономики региона является следствием эволюции бесструктурных попыток освоения ресурсов конкретных территорий (табл. 1).

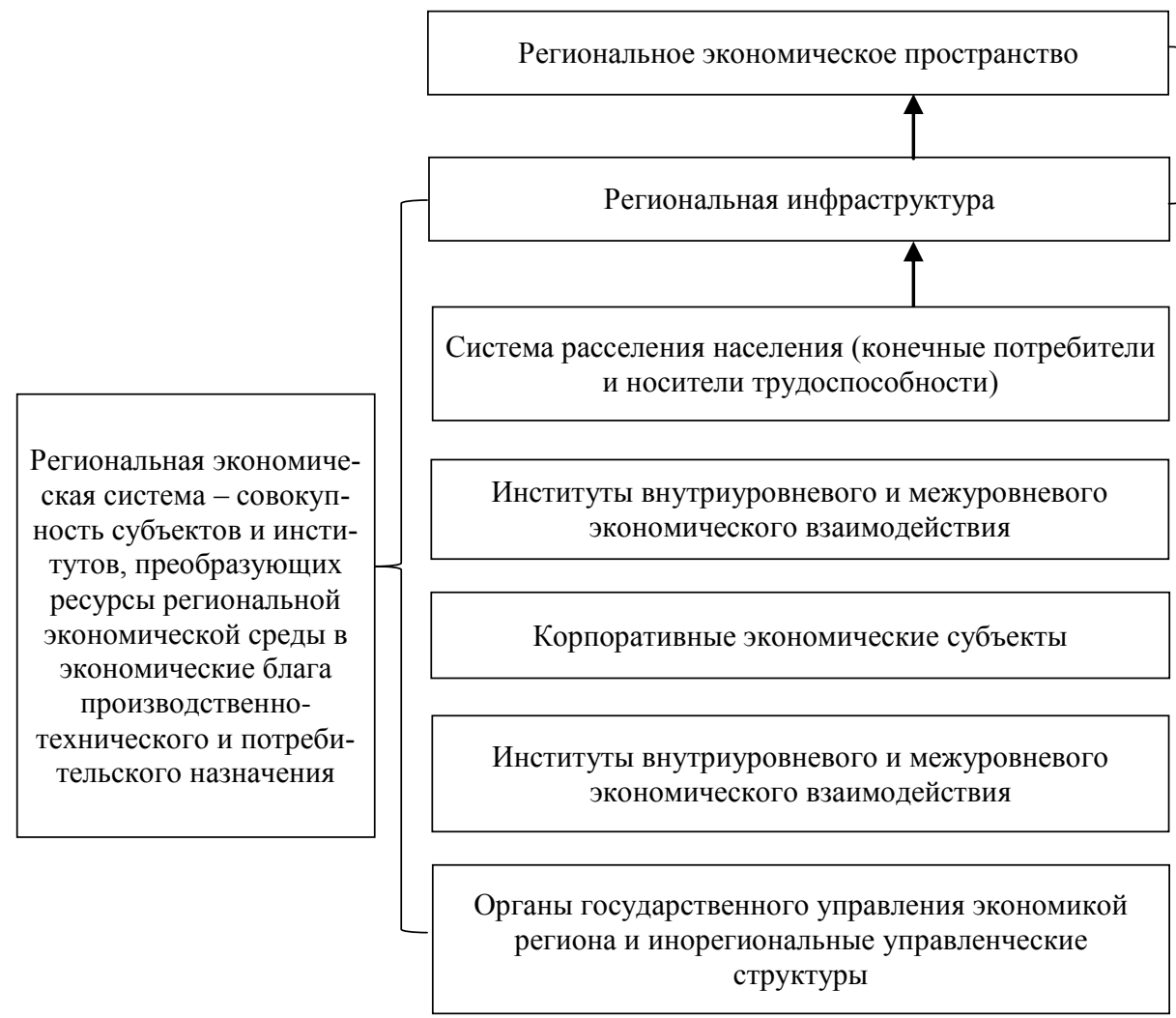

Региональная экономическая среда - совокупность систематизированных и готовых к использованию в экономической деятельности ресурсов территории

Puc. 2. Региональная инфраструктура как связующий механизм, обеспечивающий возможность использования ресурсов экономического пространства в экономической системе территории на основе формирования региональной экономической среды (авторская разработка). 
ДЕЛЕНЬЯН Б.А.

РЕГИОНАЛЬНАЯ ИНФРАСТРУКТУРА КАК ОСНОВА СИСТЕМНОГО РАЗВИТИЯ ЭКОНОМИКИ СОВРЕМЕННОГО РЕГИОНА: ПОСТАНОВКА ПРОБЛЕМЫ И ОРГАНИЗАЦИОННО-ЭКОНОМИЧЕСКОЕ ОБЕСПЕЧЕНИЕ

Таблица 1

\section{Сравнительная характеристика инфраструктурного и бесструктурного сценариев развития региональных экономических процессов (авторская разработка)}

\begin{tabular}{|c|c|c|}
\hline \multirow{2}{*}{$\begin{array}{c}\text { Ключевые характеристи- } \\
\text { ки процесса развития }\end{array}$} & \multicolumn{2}{|c|}{ Сценарии регионального экономического развития } \\
\hline & Инфраструктурный & Бесструктурный \\
\hline 1 & 2 & 3 \\
\hline $\begin{array}{l}\text { Наличие регионального } \\
\text { экономического про- } \\
\text { странства }\end{array}$ & Имеется & Имеется \\
\hline $\begin{array}{l}\text { Наличие инфраструкту- } \\
\text { ры как элемента регио- } \\
\text { нальной экономической } \\
\text { среды }\end{array}$ & Имеется & Не имеется \\
\hline $\begin{array}{l}\text { Наличие региональной } \\
\text { экономической среды как } \\
\text { совокупности ресурсов, } \\
\text { доступных в пределах } \\
\text { территории }\end{array}$ & Формирование возможно & Формирование невозможно \\
\hline $\begin{array}{l}\text { Наличие региональной } \\
\text { экономической системы }\end{array}$ & $\begin{array}{c}\text { Пространственная система узлов } \\
\text { расселения и территориальной эко- } \\
\text { номической активности, в том числе } \\
\text { локаций проживания, экономиче- } \\
\text { ской, социальной и потребитель- } \\
\text { ской активности с возможностью } \\
\text { внутрирегионального и межрегио- } \\
\text { нального маневра населения, трудо- } \\
\text { вых ресурсов, регионального чело- } \\
\text { веческого капитала, корпоративных } \\
\text { структур }\end{array}$ & $\begin{array}{c}\text { Территориальные очаги расселения и экономиче- } \\
\text { ской активности в бессистемной форме, не обеспе- } \\
\text { ченные региональными инфраструктурными ре- } \\
\text { сурсами }\end{array}$ \\
\hline $\begin{array}{l}\text { Возможность привлече- } \\
\text { ния новых резидентов в } \\
\text { региональную экономи- } \\
\text { ческую систему }\end{array}$ & $\begin{array}{c}\text { Возможна в рамках имеющихся } \\
\text { инфраструктурных возможностей } \\
\text { либо создания новых }\end{array}$ & $\begin{array}{c}\text { Возможна при условии создания собственной ин- } \\
\text { фраструктуры }\end{array}$ \\
\hline $\begin{array}{l}\text { Возможности интеграции } \\
\text { в межрайонные экономи- } \\
\text { ческие связи }\end{array}$ & $\begin{array}{c}\text { Обоснованы разницей между терри- } \\
\text { ториальным производством и по- } \\
\text { треблением экономических благ }\end{array}$ & Отсутствуют / недостаточны \\
\hline $\begin{array}{l}\text { Возможности интеграции } \\
\text { в национальные и между- } \\
\text { народные экономические } \\
\text { связи }\end{array}$ & $\begin{array}{c}\text { Обоснованы разницей между терри- } \\
\text { ториальным производством и по- } \\
\text { треблением экономических благ и } \\
\text { возможностью продуктивного ис- } \\
\text { пользования концепций специализа- } \\
\text { ции, концентрации и кооперации }\end{array}$ & Отсутствуют / недостаточны \\
\hline $\begin{array}{l}\text { Ожидаемый результат } \\
\text { стимулирующих управ- } \\
\text { ленческих воздействий }\end{array}$ & $\begin{array}{c}\text { Региональное экономическое разви- } \\
\text { тие как новое качество экономиче- } \\
\text { ских процессов. Устойчивый эконо- } \\
\text { мический рост как системный ре- } \\
\text { зультат взаимодействия факторов } \\
\text { регионального развития и ситуаци- } \\
\text { онных детерминантов } \\
\end{array}$ & $\begin{array}{c}\text { Экономический рост в пределах цикла управлен- } \\
\text { ческого воздействия как ситуационный результат } \\
\text { интенсификации региональных экономических } \\
\text { процессов }\end{array}$ \\
\hline $\begin{array}{l}\text { Ожидаемый результат } \\
\text { интеграции и участия в } \\
\text { национальных / между- } \\
\text { народных экономических } \\
\text { связях }\end{array}$ & $\begin{array}{c}\text { Интеграция экономики региона в } \\
\text { национальную экономику / глобаль- } \\
\text { ное экономическое пространство, } \\
\text { балансировка потоков инвестиций / } \\
\text { дефицитных факторов экономиче- } \\
\text { ской деятельности / результатов } \\
\text { экономической деятельности - эко- } \\
\text { номических благ, устойчивое, сба- } \\
\text { лансированное и разноплановое } \\
\text { региональное развитие }\end{array}$ & $\begin{array}{c}\text { Дезинтеграция экономического пространства, раз- } \\
\text { рыв межрегиональных и внутрирегиональных } \\
\text { экономических связей, естественная убыль населе- } \\
\text { ния и безвозвратные миграции, деградация регио- } \\
\text { нальной экономической модели до уровня нату- } \\
\text { рального хозяйства }\end{array}$ \\
\hline
\end{tabular}


Реализация инфраструктурного сценария освоения экономического потенциала территории направлена на:

- создание системного, устойчивого, безопасного и комплексного доступа к наличным и дефицитным ресурсам, необходимым для организации конкретных видов экономической деятельности;

- системное освоение пространственно-территориального ресурса на основе создания и развития сети локаций расселения, производственной, социальной и воспроизводственной активности и миграций между ними;

- привлечение новых экономических агентов-резидентов, учитывающих и рассматривающих доступ к инфраструктурным благам в качестве абсолютного или относительно экономического преимущества размещения своей деятельности в рамках конкретной территории;

- организацию деятельности территориальных производственных комплексов или их разновидностей (кластеров, индустриальных парков, промышленных округов, других мезоэкономических инфраструктурных объектов схожей функциональности), нацеленных на массовое производство и экспорт за пределы территории конкурентоспособных экономических благ;

- интеграцию в межрайонное, национальное, международное экономическое пространство на основе возможности формирования соответствующих связей и экономически эффективного их использования;

- реализацию системного подхода к обеспечению устойчивости поступательной динамики территориальной экономической активности, в том числе в случае колебания ситуационных детерминантов и демпфирования их неустойчивой конъюнктуры.

Авторская визуализация состава субъектов, инициируемых ими процессов и результатов использования инфраструктурных возможностей и потенциала в региональных экономических процессах охарактеризована на рис. 3 .

Как видно из приведенного рисунка, доступ к инфраструктурным возможностям региональной экономической среды в современном понимании возможен на основе подключения и использования возможностей узлов функциональной специализированной или универсальной инфраструктуры (отметим, что такое деление возможно даже в рамках одного вида региональной инфраструктуры: например, транспортная инфраструктура территории может быть представлена автомобильными дорогами общего пользования, специальными транспортными диаметрами, другими видами путей сообщения, функциональной и универсальной инженерной инфраструктурой, мультимодальными транспортными узлами пассажирского, грузового и смешанного назначения).

Региональные процессы использования инфраструктурных возможностей территориальной экономической среды подразумевают формирование и обработку трех ключевых экономических потоков: конверсии имеющегося потенциала, импорта дефицитных факторов и экспорта экономических благ и услуг в рамках производственной специализации территории, сопровождаемых осуществлением специфических видов экономической деятельности инфраструктурной направленности и получением их субъектами конкретных результатов. Результаты использования инфраструктурных ресурсов и возможностей в экономике региона необходимо рассматривать с двух кардинально отличающихся позиций:

1. В отношении текущих региональных экономических процессов результативность инфраструктурной деятельности связана с доступностью и стоимостью специфических ресурсов как основы экономической эффективности функционирования цепочек создания ценности регионального и межрегионального масштаба, а также возможностью импорта отсутствующих ресурсов / экспорта готовых экономических благ. Экономическая эффективность региональных инфраструктурных преобразований в данном случае может быть оценена с помощью суммы экономии инфраструктурных издержек субъектов регионального экономического процесса.

2. В отношении перспективных региональных экономических процессов, инициация которых возможна на основе создания новых пространственных инфраструктурных узлов, эффективность региональных инфраструктурных преобразований связана с системным приростом масштабов ВРП территории и всех видов доходов, перераспределяемых из его структуры (доходы населения как работников и собственников, доходы локализованных экономических агентов - корпоративных структур, доходы консолидированного бюджета), а также прогрессивным изменением состава ВРП (роста операционного результата инфраструктурных видов деятельности, опережающей динамики результата видов деятельности в части специализации территории). 
ДЕЛЕНЬЯН Б.А.

РЕГИОНАЛЬНАЯ ИНФРАСТРУКТУРА КАК ОСНОВА СИСТЕМНОГО РАЗВИТИЯ ЭКОНОМИКИ СОВРЕМЕННОГО РЕГИОНА: ПОСТАНОВКА ПРОБЛЕМЫ И ОРГАНИЗАЦИОННО-ЭКОНОМИЧЕСКОЕ ОБЕСПЕЧЕНИЕ

\begin{tabular}{|c|c|c|c|}
\hline Локализованные в реги- & Инорегиональные & Локализованные в реги- & Инорегиональные \\
\hline & & & \\
\hline \multicolumn{2}{|c|}{$\begin{array}{c}\text { Предприятия добывающей промышленности - постав- } \\
\text { щики ресурсов из регионального экономического про- } \\
\text { странства }\end{array}$} & \multicolumn{2}{|c|}{$\begin{array}{c}\text { Производители и поставщики инфраструктурных ре- } \\
\text { сурсов }\end{array}$} \\
\hline \multicolumn{2}{|c|}{$\begin{array}{c}\text { Функциональные субъекты региональной инфра- } \\
\text { структуры: узлы международного, национального } \\
\text { (межрегионального), регионального (межлокального), } \\
\text { локального значения }\end{array}$} & \multicolumn{2}{|c|}{$\begin{array}{c}\text { Универсальные субъекты региональной инфра- } \\
\text { структуры: узлы регионального и локального значе- } \\
\text { ния (индустриальные парки, кластеры, мультимодаль- } \\
\text { ные транспортные узлы) }\end{array}$} \\
\hline \multicolumn{4}{|c|}{$\begin{array}{l}\text { Процессы использования инфраструктурных ресурсов и возможностей в экономике региона: } \\
\text { 1. Конверсия природных ресурсов из регионального экономического пространства и их преобразование в экономи- } \\
\text { ческие ресурсы / факторы производства, доступные в рамках региональной экономической среды. } \\
\text { 2. Импорт на территорию региона дефицитных ресурсов и продукции/услуг. } \\
\text { 3. Экспорт с территории региона продукции отраслей специализации (ресурсов, продукции, услуг). } \\
\text { 4. Маневр (перемещение) всех видов ресурсов. } \\
\text { 5. Маневр населения, связанный с маятниковыми и безвозвратными миграциями. } \\
\text { 6. Предоставление доступа к инфраструктурным экономическим благам для пользователей - субъектов региональ- } \\
\text { ной экономической системы (инфраструкурных и конечных). } \\
\text { 7. Осуществление инфраструктурных видов экономической деятельности и получение операционных, социальных, } \\
\text { бюджетных, народнохозяйственных результатов. }\end{array}$} \\
\hline \multicolumn{4}{|c|}{$\begin{array}{l}\text { Результаты использования инфраструктурных ресурсов и возможностей в экономике региона: } \\
\text { Доступность инфраструктурных ресурсов. } \\
\text { Себестоимость и цена использования инфраструктурных ресурсов. } \\
\text { Возможность экономически эффективного использования ресурсов региональной экономической среды в цепочках } \\
\text { создания ценности субъектов региональной экономической системы. } \\
\text { Возможность экспорта инфраструктурных ресурсов региональной экономической среды. } \\
\text { Возможность экспорта результатов экономической деятельности производительных субъектов экономики региона. } \\
\text { Объемы реализации инфраструктурных ресурсов и вклад инфраструктурных субъектов в формирование итогов } \\
\text { функционирования экономики региона. }\end{array}$} \\
\hline
\end{tabular}

Рис. 3. Субъекты, процессы и результаты использования инфраструктурных возможностей и потенцииала в региональных экономических процессах (авторская разработка).

Это направление расчета и оценивания экономической эффективности региональных инфраструктурных преобразований является значимой народнохозяйственной проблемой, содержание которой связано с оценкой перспективы роста использования потенциала территории при условии его полноценного инфраструктурного обеспечения с понесением инвестиционных и эксплуатационных затрат и необходимостью их компенсации.

Расчет мультипликатора экономического развития территории как объективного обоснования региональных программ инфраструктурного развития требует своего дальнейшего научного поиска и предложения соответствующих методик и инструментов.

Авторская разработка организационно-экономической характеристики и народнохозяйственного значения региональной транспортной инфраструктуры в составе инфраструктуры экономики региона представлена на рис. 4.

Как видно из приведенного рисунка, в авторской интерпретации региональная транспортная инфраструктура, являясь функциональным элементом всей инфраструктурной подсистемы региональной экономики, в общем случае ориентирована на реализацию трех операционных функций:

- транспортной;

- логистической;

- обеспечения универсальных узлов региональной инфраструктуры функциональным набором транспортно-логистических услуг. 
В числе целей и задач создания и эксплуатации региональных инфраструктурных объектов и путей сообщения необходимо отметить полный, надежный и эффективный охват территории региона и включенных в него локаций, а также выстраивание межрегиональных транспортных связей и коридоров со смежными и несмежными регионами, осуществление процессов мобильности факторов экономической активности и населения, а также вывоза продукции отраслей специализации.

Региональная транспортная инфраструктура - функциональная разновидность региональной инфраструктуры, обеспечивающая возможность приема / передачи / транзита транспортных потоков грузового, пассажирского и смешанного характера, дифференцированных по масштабам и дальности перевозок и непосредственно перемещаемых в пределах границ территории региона экономическими агентами пользователями возможностей РТИ

Функции региональной транспортной инфраструктуры

Перемещение грузов и пассажиров в пределах региональной транспортной инфраструктуры (транспортная функция): 1) От транспортного хаба национального масштаба: прием, перевалка / перераспределение, транспортировка / перемещение до конечного пункта. 2) Между границами региона / транспортными хабами национального масштаба (региональный и межрегиональный транзит). 3) От пункта отправления в транспортный хаб национального масштаба с последующей интеграцией в межрегиональный / национальный транспортный поток.

Обработка и управление формированием и динамикой межлокальных (региональных) и межрегиональных транспортных потоков (логистическая функция): складирование / накопление, хранение, комплектование / разукомплектование транспортных партий, контроль наличия / качества / сохранности / убыли грузов, прием / выдача грузов перевозчикам, взаимодействие между хабами регионального масштаба

Обеспечение региональных универсальных узлов инфраструктуры транспортно-логистическими возможностями по обслуживанию входящих и исходящих транспортных потоков

Цели и задачи создания и развития региональной транспортной инфраструктуры

1) Полный охват территории региона и удовлетворение народнохозяйственной потребности в привозе / перемещении дефицитных физических ресурсов, необходимых для функционирования и развития экономики и социальной сферы региона. 2) Удовлетворение потребности в межлокальном (региональном) и межрегиональном маневре всеми факторами экономической деятельности (кроме земли, недвижимости и информации). 3 ) Удовлетворение потребности в мобильности населения (резиденты, мигранты). 4) Удовлетворение потребности в вывозе продукции отраслей специализации экономики региона. 5) Сопровождение и обработка транзитных транспортных потоков, затрагивающих территорию региона. 6) Участие в формировании точек и полюсов регионального развития.

Операционные и народнохозяйственные результаты создания и развития региональной транспортной инфраструктуры

Операционные результаты: 1) Показатели операционной деятельности инфраструктурных предприятий, сетей и узлов. 2) Показатели финансовой и инвестиционной деятельности инфраструктурных предприятий, сетей и узлов.

Народнохозяйственные результаты: 1) Экономия ресурсов пользователей, связанная с интеграцией транспортных потоков и их единым транспортным обслуживанием. 2) Эффективный доступ к межрегиональным и международным транспортным потокам и коридорам. 3) Вклад в формирование экономических, социальных, бюджетных и воспроизводственных итогов функционирования региональной экономики.

Стратегический результат: создание, системный охват территориальных транспортных потоков на основе непрерывного функционирования транспортных узлов оптимального формата и мощности, позволяющих обеспечить эффективное сопровождение внутрирегиональных и межрегиональных транспортных потоков (как имеющихся, так и перспективных) на основе принципов централизации и специализации, мультимодальности, безопасного, равного и справедливого (без дискриминационного) доступа, демпфирования колебаний параметров транспортных потоков, доступности для новых экономических агентов, существенного вклада в формирование итогов экономических процессов и конкурентоспособности региональной экономики.

Pис. 4. Региональная транспортная инфраструктура в составе инфраструктуры экономики региона: организационно-экономическая характеристика и народнохозяйственное значение (авторская разработка). 
РЕГИОНАЛЬНАЯ ИНФРАСТРУКТУРА КАК ОСНОВА СИСТЕМНОГО РАЗВИТИЯ ЭКОНОМИКИ СОВРЕМЕННОГО РЕГИОНА: ПОСТАНОВКА ПРОБЛЕМЫ И ОРГАНИЗАЦИОННО-ЭКОНОМИЧЕСКОЕ ОБЕСПЕЧЕНИЕ

Актуальной инфраструктурной задачей регионального масштаба является также функциональная транспортно-логистическая поддержка процессов формирования региональных точек и полюсов роста.

Подчеркнем также необходимость системного получения, оценки и интерпретации операционных, народнохозяйственных и стратегического результатов, связанных с ролью и значением транспортной инфраструктуры и ее компонентов в региональных экономических процессах. В стратегии ее народнохозяйственное значение связано с полным и непрерывным охватом транспортными перемещениями всех локальных и межлокальных (региональных) экономических процессов потребительского и производительного характера, а также поддержкой региональной воспроизводственной активности и функции пространственно-территориального развития. В идеале при точном и обоснованном пространственном планировании региональная транспортная структура может стать точкой инициации региональных комплексных проектов освоения территорий, обеспечив самостоятельный значимый вклад в формирование итогов экономических процессов и рост региональной конкурентоспособности.

Для комплексной характеристики перспектив функционирования и развития региональной инфраструктуры морского транспорта, представленной в Краснодарском крае в контексте усиления его стратегического значения в составе национального транспортного комплекса, нами было реализовано авторское исследование в форме глубинного интервью, база респондентов которого была сформирована на основе привлечения представителей предприятий - собственников морских судов и портовой инфраструктуры Краснодарского края.

Экспертные оценки респондентов в части состояния и эффективности функционирования портовой инфраструктуры морского транспорта Краснодарского края могут быть охарактеризованы следующим образом. Респонденты в целом достаточно высоко оценивали параметры функционирования отечественной портовой инфраструктуры, отмечая в целом высокий уровень безопасности процессов грузопереработки (средняя оценка 4,3 из 5 возможных), наличие необходимых железнодорожных путей $(4,2)$ и качество грузопереработки $(4,2)$. В то же время респонденты были недовольны недостаточным уровнем функциональности систем сопряжения грузопотоков между различными видами транспорта, указывали на возможные резервы в скорости переработки грузов и связанные с этим простои судов по вине портов, а также отмечали необходимость дальнейшего развития систем планирования и диспетчеризации грузопотоков.

О в целом нормальном функционировании региональной портовой инфраструктуры Краснодарского края свидетельствует тот факт, что $73 \%$ респондентов не оценили порты региона как «узкое место» корпоративного грузопотока, 86,7 \% опрошенных отметили высокую и достаточную конкурентоспособность региональных портов даже в сравнении с иностранными конкурентами, 76 \% опрошенных подчеркнули наличие некоторых резервов снижения стоимости своих услуг за счет оптимизации портово-перегрузочной деятельности. У 60 \% опрошенных в 2018 году имелись собственные причальные сооружения, при этом реализованные в последние годы проекты создания новых портовых мощностей респонденты характеризовали очень сдержанно, отмечая отсутствие существенного народнохозяйственного значения вновь созданных портовых мощностей.

36,7 \% опрошенных в своей транспортной деятельности имели операционные контакты с портами Украины, при этом только 16,7 \% опрошенных планировали продолжать сотрудничество в 2018-2020 годах.

Проведенное исследование позволило получить следующие результаты:

- нынешний уровень наличия и функционирования региональной инфраструктуры морского транспорта в Краснодарском крае был оценен представителями организаций морского транспорта достаточно высоко, хотя была отмечена асимметричность в перспективном развитии инфраструктуры в пользу аффилированных компаний;

- стратегическое управление региональной транспортной инфраструктурой морского транспорта в Краснодарском крае характеризовалось наличием определенных резервов, связанных как с перспективными направлениями роста возможностей и значимости морского транспорта в решении крупных народнохозяйственных задач, так и с преодолением асимметричности в выработке и реализации стратегических решений развития (например, в части государственной поддержки программ строительства новых грузовых судов). 
Лuтература

1. Бекямев Д. К. Правовое регулирование дисичилины труда на судах рыбопромыслового флота и морского транспорта РФ // Рыббое хозяйство. - 2004. - № 4. - С. 69.

2. Воронов А. А. Конкуренциия и конкурентоспособность: количественные методы оценки. Монография. Краснодар, КубГУ, 2002.

3. Еникеева Л. А., Торосян Е. К., Фейлинг Т. Б. Формирование стратегий развития морского и речного транспорта РФ на фоне кризисных процессов в условиях глобальной нестабильности мировых экономических систем // Вестник государственного университета морского и речного флота им. адмирала С. О. Макарова. - 2014. - № 6 (28). - C. 163-173.

4. Ибрагимов М. Т. А., Дохолян С. В. Методические подходы к оиенке состояния продовольственной безопасности региона // Региональные проблемы преобразования экономики. - 2010. - № 4. - С. 172 193.

5. Кундин Н. Б. Установление истины по уголовным делам, возбужденным в связи с нарушением правил безопасности движения и эксплуатачии морского и внутреннего водного транспорта (cm. 263 УК РФ) // Вестник Волжской государственной академии водного транспорта. - 2012. - № 33. - C. 33-35. 6. Леонтьев Р. Г. Транспорт и логистика Дальнего Востока РФ: водный (морской и речной) и воздушный транспорт / Р. Г. Леонтьев. Хабаровск, Министерство транспорта Российской Федерации, Федеральное агентство ж.-д. транспорта, ГОУ ВПО «Дальневосточный гос. ун-т путей сообщ..» 2008. $231 \mathrm{c}$.

7. Леонтьев Р. Г., Адаменя А. И. Особенности морского транспорта Дальнего Востока РФ // Бюллетень транспортной информации. - 2008. - № 12. - С. 17-22.

8. Плавучая атомная теплоэлектростанция (ПАТЭС) «Академик Ломоносов». [Электронный ресурс]. Режим доступа: https://al-lobanov.livejournal.com/1292062.html, свободный. - Загл. с экрана.

9. Сабайдаш М. В. Методика расчета уровня налоговой нагрузки по предприятиям морского транспорта РФ для оценки бюджетной эффективности инвестиционного проекта // Эксплуатация морского транспорта. - 2008. - № 2. - C. 3-5.

10. Самуэльсон П., Нордхаус У. Экономика. - М.: Вильямс, 2014. - С. 55.

11. Сердитов С. В. Динамика развития и использования логистической инфраструктуры на морском транспорте РФ // Форум молодых ученых. - 2017. - № 6 (10). - С. 1570-1577.

12. Тарасова Е. В. Исследование и анализ основных проблем морского и водного видов транспорта РФ с иелью выявления способов их решения // NovaInfo.Ru. - 2015. - T. 1. - № 33. - C. 95-101.

13. Bola A. Potential for sustainable sea transport: A case study of the Southern Lomaiviti, Fiji islands // Marine Policy. 2017. Vol. 75. P. 260-270.

14. Newell A., Nuttall P., Prasad B., Veitayaki J. Turning the Tide: the need for sustainable sea transport in the Pacific // Marine Policy. 2017. Vol. 75. P. 249-259.

15. Rusu L. I. Economic Efficiency of Sea Transport. Case Study // Procedia Economics and Finance. 2015. Vol. 32. P. 1598-1607.

16. [Электронный ресурс]. Режим доступа: http://fb.ru/article/214654/obschaya-protyajennost-granitsrossii/, свободный. - Загл. с экрана.

17. [Электронный ресурс]. Режим доступа: http://portnews.ru/comments/2200//, свободный. - Загл. с экрана.

18. [Электронный ресурс]. Режим доступа: http://www.gks.ru/wps/wcm/connect/rosstat_main/rosstat/ru/ statistics/ enterprise/transport/, свободный. - Загл. с экрана.

19. [Электронный ресурс]. Режим достуnа: http://xindemarinenews.com/en/market/2018/0202/2339.html/, свободный. - Загл. с экрана.

20. [Электронный ресурс]. Режим доступа: https://narfu.ru/aan/, свободный. - Загл. с экрана.

\section{References:}

1. Bekyashev D. K. Pravovoe regulirovanie discipliny truda na sudah rybopromyslovogo flota $i$ morskogo transporta RF // Rybnoe hozyajstvo. - 2004. - № 4. - S. 69.

2. Voronov A. A. Konkurenciya i konkurentosposobnost': kolichestvennye metody ocenki. Monografiya. Krasnodar, KubGU, 2002.

3. Enikeeva L. A., Torosyan E. K., Fejling T. B. Formirovanie strategij razvitiya morskogo i rechnogo transporta RF na fone krizisnyh processov v usloviyah global'noj nestabil'nosti mirovyh ekonomicheskih sistem // Vestnik gosudarstvennogo universiteta morskogo i rechnogo flota im. admirala S. O. Makarova. - 2014. - № 6 (28). - S. 163-173.

4. Ibragimov M. T. A., Doholyan S. V. Metodicheskie podhody $k$ ocenke sostoyaniya prodovol'stvennoj bezopasnosti regiona // Regional'nye problemy preobrazovaniya ekonomiki. - 2010. - № 4. - S. 172-193.

5. Kundin N. B. Ustanovlenie istiny po ugolovnym delam, vozbuzhdennym v svyazi s narusheniem pravil bezopasnosti dvizheniya i ekspluatacii morskogo $i$ vnutrennego vodnogo transporta (st. 263 UK RF) // Vestnik Volzhskoj gosudarstvennoj akademii vodnogo transporta. - 2012. - № 33. - S. 33-35.

6. Leont'ev R. G. Transport $i$ logistika Dal'nego Vostoka RF: vodnyj (morskoj $i$ rechnoj) $i$ vozdushnyj transport / R. G. Leont'ev. Habarovsk, Ministerstvo transporta Rossijskoj Federacii, Federal'noe agentstvo zh.d. transporta, GOU VPO «Dal'nevostochnyj gos. un-t putej soobshch.» 2008. - 231 s.

7. Leont'ev R. G., Adamenya A. I. Osobennosti morskogo transporta Dal'nego Vostoka RF // Byulleten' transportnoj informacii. - 2008. - № 12. - S. 17-22.

8. Plavuchaya atomnaya teploelektrostanciya (PATES) «Akademik Lomonosov». [Elektronnyj resurs]. Rezhim dostupa: https://al-lobanov.livejournal.com/1292062.html, svobodnyj. - Zagl. s ekrana.

9. Sabajdash M. V. Metodika rascheta urovnya nalogovoj nagruzki po predpriyatiyam morskogo transporta $R F$ 
РЕГИОНАЛЬНАЯ ИНФРАСТРУКТУРА КАК ОСНОВА СИСТЕМНОГО РАЗВИТИЯ ЭКОНОМИКИ СОВРЕМЕННОГО РЕГИОНА: ПОСТАНОВКА ПРОБЛЕМЫ И ОРГАНИЗАЦИОННО-ЭКОНОМИЧЕСКОЕ ОБЕСПЕЧЕНИЕ

dlya ocenki byudzhetnoj effektivnosti investicionnogo proekta // Ekspluataciya morskogo transporta. - 2008. № 2. - S. 3-5.

10. Samuel'son P., Nordhaus U. Ekonomika. - M.: Vil'yams, 2014. - S. 55.

11. Serditov $S$. V. Dinamika razvitiya i ispol'zovaniya logisticheskoj infrastruktury na morskom transporte RF // Forum molodyh uchenyh. - 2017. - № 6 (10). - S. 1570-1577.

12. Tarasova E. V. Issledovanie $i$ analiz osnovnyh problem morskogo i vodnogo vidov transporta $R F$ s cel'yu vyyavleniya sposobov ih resheniya // NovaInfo.Ru. - 2015. - T. 1. - № 33. - S. 95-101.

13. Bola A. Potential for sustainable sea transport: A case study of the Southern Lomaiviti, Fiji islands // Marine Policy. 2017. Vol. 75. P. 260-270.

14. Newell A., Nuttall P., Prasad B., Veitayaki J. Turning the Tide: the need for sustainable sea transport in the Pacific // Marine Policy. 2017. Vol. 75. P. 249-259.

15. Rusu L. I. Economic Efficiency of Sea Transport. Case Study // Procedia Economics and Finance. 2015. Vol. 32. P. 1598-1607.

16. [Elektronnyj resurs]. Rezhim dostupa: http://fb.ru/article/214654/obschaya-protyajennost-granits-rossii/, svobodnyj. - Zagl. s ekrana.

17. [Elektronnyj resurs]. Rezhim dostupa: http://portnews.ru/comments/2200//, svobodnyj. - Zagl. s ekrana.

18. [Elektronnyj resurs]. Rezhim dostupa: http://www.gks.ru/wps/wcm/connect/rosstat main/rosstat/ru/ statistics/ enterprise/transport/, svobodnyj. - Zagl. s ekrana.

19. [Elektronnyj resurs]. Rezhim dostupa: http://xindemarinenews.com/en/market/2018/0202/2339.html/, svobodnyj. - Zagl. s ekrana.

20. [Elektronnyj resurs]. Rezhim dostupa: https://narfu.ru/aan/, svobodnyj. - Zagl. s ekrana. 